\title{
CINHIMES - REPENSAR O MUNDO PELAS LENTES DA ARTE
}

\author{
CINHIMES - RETHINKING THE WORLD BY ART LENS
}

\author{
Everson Nicolau de Almeida ${ }^{1}$ e Angelo Adriano Faria de Assis².
}

1 Pós-Graduação em Letras (estudos Literários), Universidade Federal de Viçosa, Brasil, e-mail: eversonscj@gmail.com, orcid.org/0000-0002-7356-2544

2, Professor Associado III do Departamento de História, Universidade Federal de Viçosa Brasil, e-mail: angeloassis@ufv.br, orcid.org/0000-0002-1587-438X

\author{
ARTICLE INFO \\ Article history: \\ Received 2019-09-20 \\ Accepted 2019-12-14 \\ Available online 2019-12-14
}

Palavras-chave: Literatura, História, Memória, Cinema, Narrativa.

Keywords: Literature, History, Memory, Cinema, Narrative.

RESUMO. O NHIMES é um grupo de discussão, estudo e produção do conhecimento em História, nucleado no Departamento de História da UFV, que congrega estudiosos (alunos, professores) que compartilham entre si da consciência de que a história é uma forma de hierarquizar, preservar e produzir a memória (seja em seus domínios formais e acadêmicos, seja como memória coletiva, transformação do espaço ou monumento) que se caracteriza pela narratividade. Dessa forma, os pesquisadores do NHIMES orientam os seus estudos para o fenômeno da história enquanto memória exteriorizada, marcado por uma racionalidade e uma objetividade próprias, oriundas de seus contextos de criação (institucionais, sociais ou geográficos). O universo de inspeção privilegiado pelo grupo é composto de um arquivo que não se resume ao universo burocrático dos textos oficiais, mas estendido aos textos literários, aos conhecimentos formais da disciplina histórica, às memórias e narrativas de viajantes, às transformações do espaço e às intervenções na natureza promovidas pela ação humana. As linhas de pesquisa do grupo encontram-se assim divididas: Narrativas e suas fronteiras discursivas, Identidades, Imaginário e Representações da Memória, Espaço e Instituições. O grupo pretende ser um espaço aberto à interlocução com os temas acima relacionados, explorando suas questões teóricas subjacentes e servindo como local privilegiado para nuclear projetos que investiguem diferentes arquivos $e$ recortes espaço-temporais na modernidade. Para tanto, entre seus objetivos, ressaltam-se: formar especialistas dentro da comunidade acadêmica; reunir fontes documentais e bibliografia específica; realizar atividades de extensão que envolvam pesquisadores convidados e a comunidade; produzir e divulgar textos de caráter acadêmico. 
O CINHIMES é uma atividade realizada pelo Laboratório NHIMES - Narrativas, Histórias, Identidades e Memórias Sociais, vinculado ao Departamento de História da Universidade Federal de Viçosa (Figura 1). Ao longo de seus quase dez anos de trajetória, o NHIMES tem incentivado o contato entre a História e outros campos do conhecimento, buscando diálogos que permitam a pesquisadores e ao público em geral a discussão de temáticas que auxiliem na compreensão do devir histórico e das transformações ocorridas na sociedade, ciente de que não cabe apenas aos historiadores o olhar sobre o passado. Agrupam-se no laboratório professores, estudantes de graduação e pós-graduação e bolsistas de iniciação científica, com pesquisas que tratam de temas relevantes para a compreensão da sociedade em seus aspectos históricos, econômicos e socioculturais.

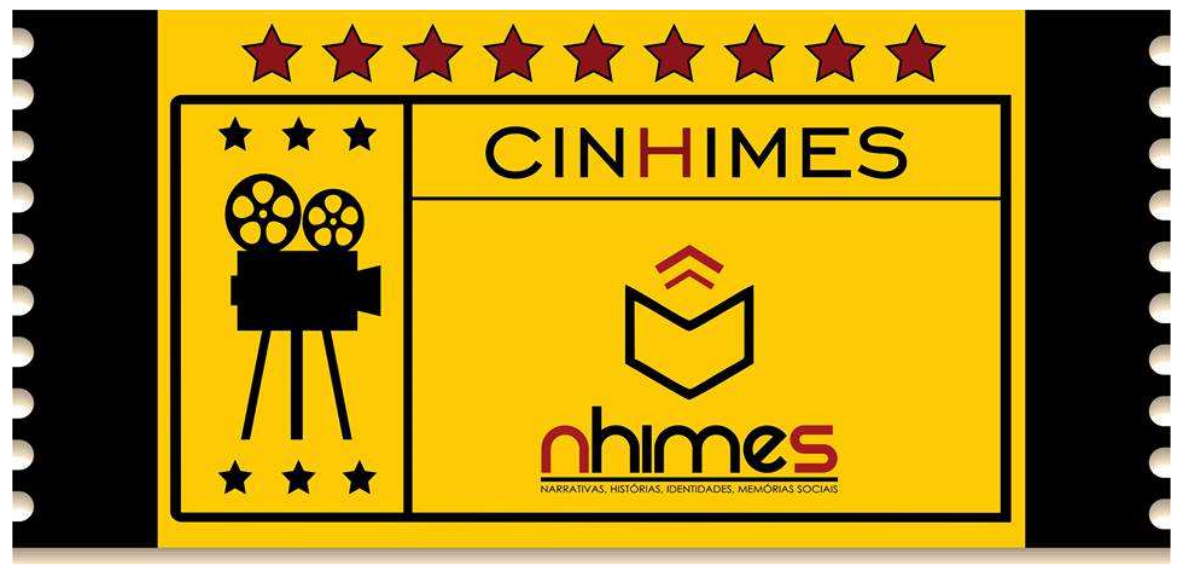

Figura 1 - Logo do evento.

Atentos à necessidade de diálogo entre universidade e sociedade e, ao mesmo tempo, sensíveis às demandas dos grupos sociais que integram o espaço acadêmico, os membros do laboratório decidiram criar uma mostra de cinema com o intuito de contribuir para o debate científico em diálogo com temas atuais, visando, assim, a formação complementar de estudantes e proporcionando novos conhecimentos à sociedade em geral, sempre convidada a participar deste diálogo. Deste modo, o evento CINHIMES (Cinema, Narrativas, Histórias, Identidades e Memórias Sociais) surgiu como uma proposta de exibição de filmes que tratam de assuntos importantes para a formação de professores e para (in)formação da sociedade como um todo, a fim de inserir os participantes em questões que despertem interesse e auxílio na compreensão de situações atuais. Neste intuito, o tema escolhido para a primeira mostra CINHIMES, realizada nos últimos dias 23 e 24 de agosto no auditório do DLA (Departamento de Letras- UFV) foi Gênero e Sexualidade (Figura 2). 
O laboratório NHIMES (NARRATIVAS, HISTÓRIAS, IDENTIDADES E MEMÓRIAS SOCIAIS) realizará nos próximos dias 23 e 24 de agosto (quinta e sexta-feira), às $14 \mathrm{~h}$, o 1 은 CINHIMES (CINEMA, NARRATIVAS, HISTÓRIAS, IDENTIDADES E MEMÓRIAS SOCIAIS). O evento acontecerá no auditório do Departamento de Letras (DLA) da Universidade Federal de Viçosa (UFV). Para esta primeira edição, o evento terá como tema Gênero e Sexualidade, discutido a partir do filme Preciosa-Uma história de Esperança (2009).

Confiram a programaçăo do evento:

Quinta-feira (23/08) - 14h - exibição do filme no auditório do DLA - UFV

Sexta-feira (24/08) - 14h - Mesa-redonda e debate sobre o tema Gênero e Sexualidade no auditório do DLA

Convidados:

Prof. Dr. Luiz Ismael Pereira (DPD-UFV)

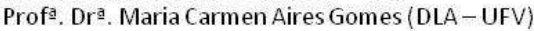

Vereadora Brenda Santunioni

Miguel Orlando da Fonseca (Direito - UNIVIÇOSA)

Coordenador: Prof. Dr. Angelo Assis (DHI-UFV)

Organizaçăo: Laboratório NHIMES

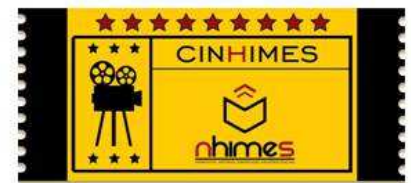

O evento será gratuito e haverá lista de presença e emissão de certificados.

Contatos:

e-mail:nhimes.ufv@gmail.com

Facebook: https://www. facebook.com/nhimes.ufv

Página do evento: https://www.facebook.com/events/2027516560804158

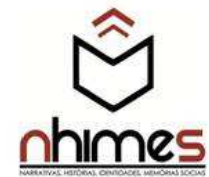

Figura 2 - Cartaz-convite.

O filme selecionado para a primeira edição da mostra foi o longa-metragem estadunidense Preciosa (Precious), lançado em 2009, sob a direção de Lee Daniels, adaptado do livro de título homônimo da romancista norte-americana Sapphire. A escolha do filme, pela própria proposta do evento, é indicação do(s) debatedor(es) convidado(s) para a atividade.

No longa-metragem é contada a história de Claireece Precious Jones, conhecida como Preciosa, uma garota de dezesseis anos, negra, obesa e analfabeta e que está grávida do seu segundo filho, fruto dos abusos sexuais aos quais era submetida por seu pai. Com uma condição social e econômica comprometida pela pobreza, Preciosa sofria também agressões físicas e psicológicas por parte de sua mãe. A vida da protagonista começa a mudar quando ela se encontra com a professora Ms. Rain, que lecionava em uma escola alternativa para meninas.

Preciosa é um filme que trata de diversos assuntos, dentre os quais estão representadas as questões de gênero e sexualidade ligadas aos fatores sociais, econômicos e raciais, tematizados em um debate realizado no dia seguinte à exibição do filme (Figura 2). 


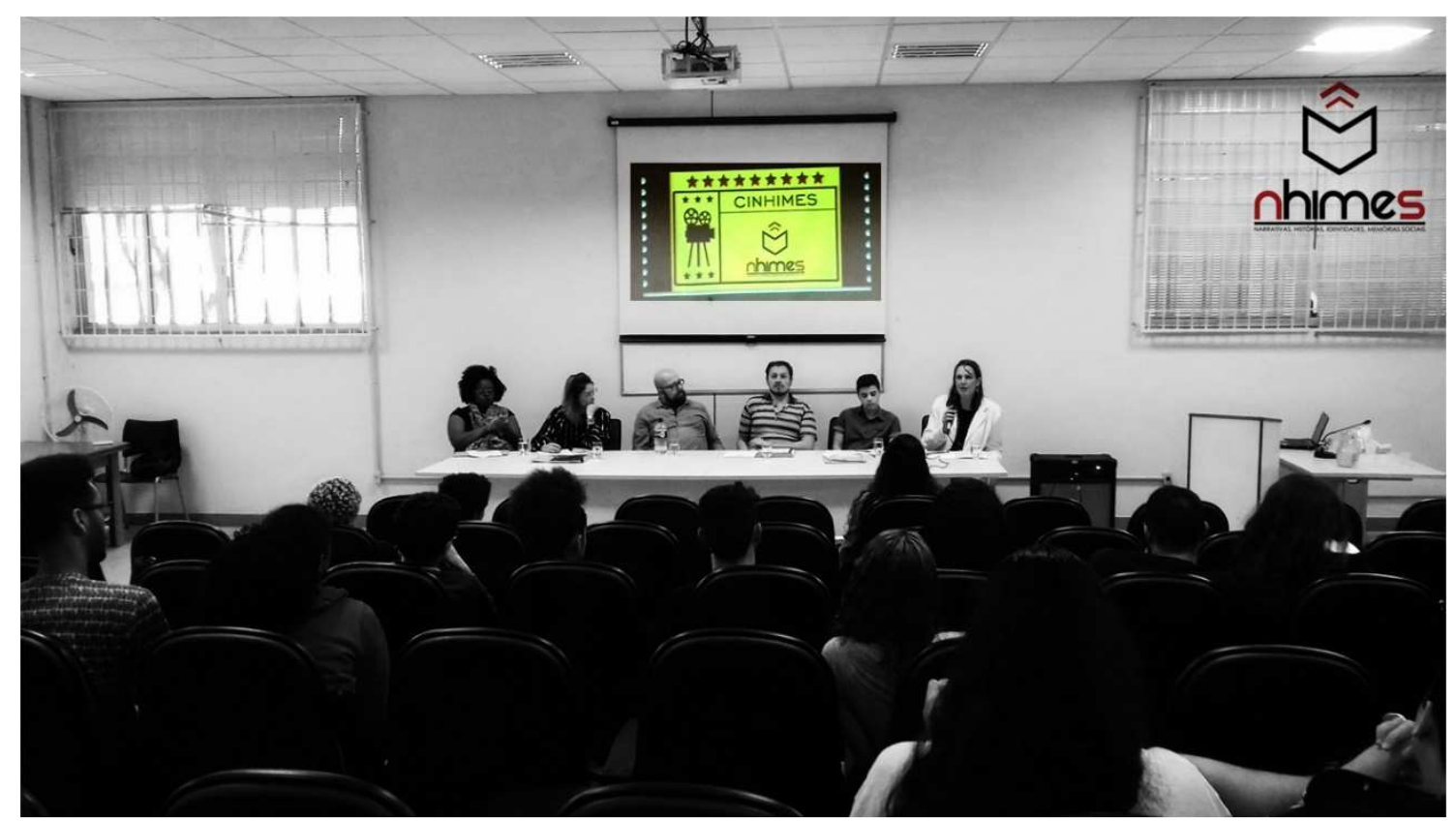

Figura 2 - Auditório do Departamento de Letras (DLA-UFV)

Para a composição de uma mesa-redonda (Figura 3), mediada pelo professor Angelo Assis (DHI-UFV), participaram os seguintes convidados: a vereadora de Viçosa, Brenda Santunioni, Miguel Orlando (discente do curso de Direito-UNIVIÇOSA), professor Luiz Ismael Pereira (DPD-UFV), professora Maria Carmem Aires Gomes (DLA-UFV) e a professora Juliana Costa (Mestra em Estudos Literários pela UFJF).

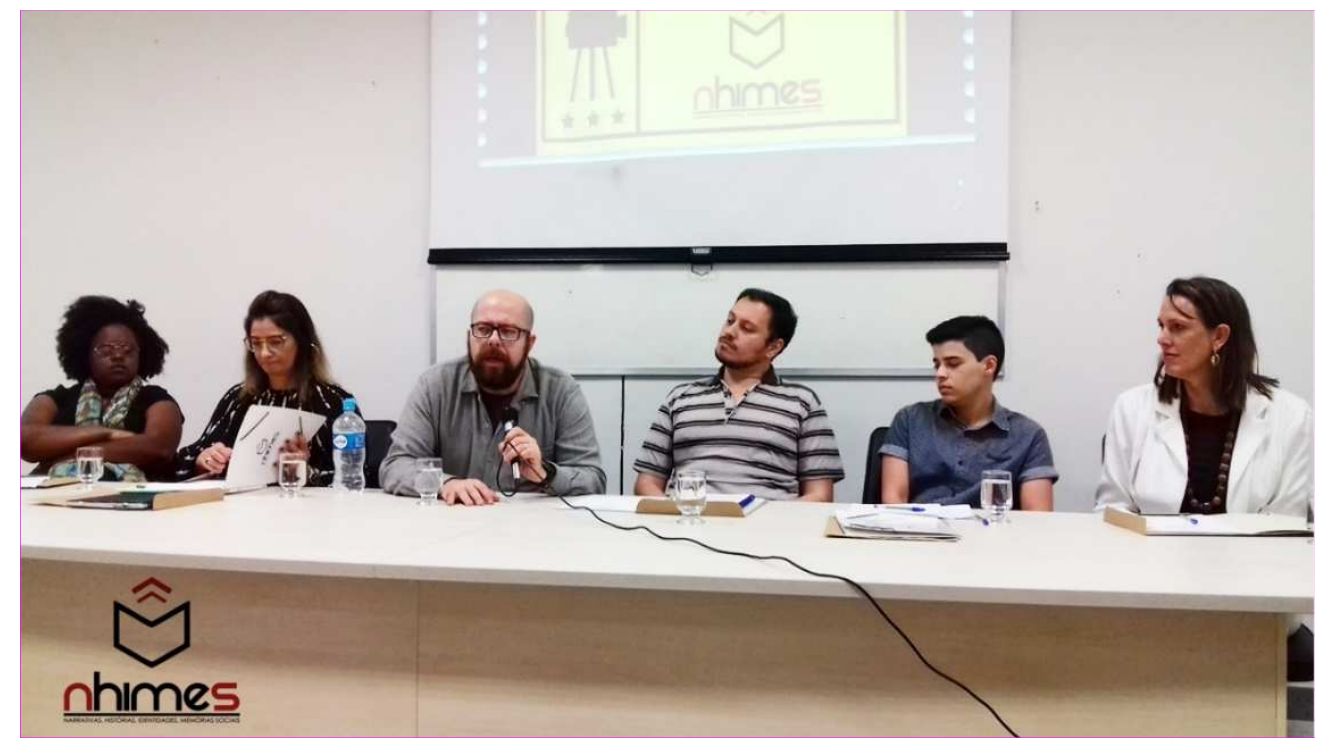

Figura 3 - Composição da Mesa - Professora Juliana Costa (Mestra em Estudos Literários pela UFJF), professora Maria Carmem Aires Gomes (DLA-UFV), professor Angelo Assis (DHI-UFV), professor Luiz Ismael Pereira (DPD-UFV), Miguel Orlando (discente do curso de Direito-UNIVIÇOSA), a vereadora de Viçosa, Brenda Santunioni. 
Em sua fala, a vereadora Brenda Santunioni elencou uma série de fatores que promovem a violência cotidiana contra os sujeitos transexuais, fazendo uma relação com as violências sofridas pela protagonista do filme. Além disso, Santunioni tratou de questões ligadas à representação da comunidade LGBTQ+ nos meios de comunicação e refletiu sobre o papel que as políticas inclusivas e as reivindicações desses grupos têm na abertura de espaços e oportunidades para os membros dessa comunidade. Além disso, Brenda contou um pouco sobre sua experiência na câmara de vereadores de Viçosa, como primeira mulher trans eleita no município para ocupar um cargo no legislativo.

O aluno do curso de Direito da Univiçosa, Miguel Orlando, também contou um pouco sobre sua experiência como homem trans, relatando um pouco o seu processo de transição e sobre o papel da família e das instituições de ensino durante esse período de mudanças. Em sua fala, Miguel deu informações relacionadas à pesquisa que realiza acerca de mulheres transexuais em situação de cárcere, chamando a atenção dos presentes para a necessidade de formação e de informação por parte da sociedade sobre as situações vividas naquele contexto. Dando continuidade, o convidado abordou a importância do cuidado e do acolhimento de pessoas que estão em situações de vulnerabilidade, como fora visto no filme exibido no dia anterior, posicionando-se contra todo e qualquer tipo de violência em seus diversos níveis. Miguel finalizou suas colocações indicando a leitura das obras de quatro autores que tratam do tema da transexualidade: João Neri, Jaqueline Gomes, Berenice Bento e Viviane Vergueiro.

Logo em seguida, tomou a palavra o professor do Departamento de Direito da UFV, Luiz Ismael Pereira. Em sua exposição, o professor refletiu sobre o papel da arte nos cursos de licenciatura e de direito, traçando uma crítica acerca da educação mecanicista que forma aquilo que ele nomeou como "técnicos dentro da técnica". Baseando-se no artigo 3o da Constituição Federal de 1988, que completou seu 30ªniversário, o professor Luiz Ismael fez um paralelo entre o longa-metragem e a constituição brasileira, atentando para as cenas em que os seguintes elementos dispostos em nossa carta magna são infringidos: liberdade, justiça, solidariedade e desenvolvimento nacional. Já no fim de sua fala, o professor chamou a atenção dos presentes para as questões sociais que geram exclusão através de forças que minam a democracia, como as formas variadas de violência, dentre as quais estão o preconceito, a injustiça e o ataque à soberania nacional através de políticas que geram exclusão dos sujeitos que integram a nossa sociedade.

Logo após a apresentação do professor Luiz Ismael tomaram a palavra a professora Maria Carmen Ayres Gomes, do Departamento de Letras e Artes da UFV e a professora Juliana Cristina Costa, mestra em Estudos Literários pela Universidade Federal de Juiz de Fora. A professora Maria Carmen discorreu sobre os marcadores discursivos no filme que apontam para as questões relacionadas aos gêneros e aos corpos e pautou sua reflexão 
nos seguintes questionamentos: "O que falar sobre corpos?", "De que corpos falamos e quais são esses marcadores de diferenças?". Maria Carmen Gomes alertou ainda para as violências cotidianas que a indiferença causa aos corpos que não importam à sociedade, o que causa lástima e contribui para o aumento da miséria humana. Logo em seguida, a professora Juliana Costa traçou uma crítica aos padrões estéticos que normatizam a ideia de beleza, e, com base em sua pesquisa de mestrado sobre escritas femininas, refletiu acerca do apagamento das mulheres negras ao longo da história, enfatizando seu protagonismo, em uma relação direta com algumas partes do filme. Além disso, Costa afirmou a importância do debate de temas como gênero, sexualidade e negritude, a fim de que algumas pautas tenham espaço dentro das universidades, ressaltando a importância da diversidade de representações e reivindicações dos sujeitos que integram o espaço universitário.

Por fim, o professor Angelo Assis fez um apanhado geral sobre as falas dos membros da mesa e logo em seguida abriu o debate para as perguntas dos participantes. Dentre as questões levantadas, destacaram-se a falta de espaço e de transversalidade de temas emergentes nas disciplinas e as metodologias para abordar diversidade em sala aula com estudantes dos ensinos fundamental e médio.

O CINHIMES, em sua primeira edição, foi encerrado após as perguntas dos ouvintes e já contou com mais edições: em setembro de 2018, com a exibição do filme "The Witch", baseado no tema gênero e práticas mágico-religiosas na idade moderna, debatido pelo professor Marcus Vinicius Reis, doutorando em história pela UFMG; e em março de 2019, com o filme "Roma", debatido pela professora Priscilla Dorella (DHI-UFV), que enfatizou as relações históricas, econômicas e socioculturais da América Latina.

A proposta do CINHIMES obteve êxito na comunidade acadêmica a ponto de ser ampliada e, em abril de 2019, o evento se transformou em uma semana de debates intitulada Narrativas em Tempos de Crise, em parceria inter-institucional entre o NHIMES e os núcleos de estudos NECLI (Núcleo de Estudos Comparados em Literatura), coordenado pelos professores Rodrigo Garcia Barbosa e Roberta Guimarães Franco e NECIM (Narrativas, Estudos Culturais, Identidades e Memórias), coordenado pela Roberta Guimarães Franco. Os dois núcleos de estudo parceiros do NHIMES estão alocados no Departamento de Estudos da Linguagem, na Universidade Federal de Lavras (DEL-UFLA). As discussões oriundas deste evento serão lançadas em um livro que deve ser lançado já no primeiro semestre de 2020. Além disto, estão previstas novas edições, tanto do CINHIMES quanto de eventos que fortaleçam as parcerias entre o NHIMES, o NECLI e o NECIM, em prol de uma universidade cada vez mais democrática e que dialogue sobre os problemas da sociedade em que vivemos.

\section{REFERÊNCIA}

PRECIOSA: uma história de esperança. Direção Lee Daniels. EUA: PlayArt, 2009. DVD. 